\title{
High prevalence of pathogenic Leptospira in alien American mink (Neovison vison) in Patagonia
}

\author{
Macarena Barros', Leonardo Sáenz², Lisette Lapierre², Camila Nuñez ${ }^{2}$ and Gonzalo Medina-Vogel ${ }^{*}$
}

\begin{abstract}
Background: Leptospirosis is an important zoonosis with worldwide distribution caused by pathogenic bacteria of the genus Leptospira. The North American mink (Neovison vison) has an important role in the environmental contamination with Leptospira, as minks live in aquatic environments and are the predators of rodents.

Findings: Blood and kidney samples were obtained from 57 minks in Southern Chile $39^{\circ} \mathrm{S}$ to $45^{\circ} \mathrm{S}$. Pathogenic species of Leptospira were detected by PCR on 31/57 minks. To determine the species, we sequenced the 16S ribosomal RNA (rRNA) gene on nine of the positive samples. We predicted two pathogenic species: Leptospira interrogans (five samples) and Leptospira borgpetersenii (four samples).

Conclusions: This study showed that the American mink presents pathogenic species of Leptospira and confirm important environmental contamination of Patagonian rivers and lakes with pathogenic Leptospira.
\end{abstract}

Keywords: Pathogen Leptospira; Alien North American mink; Patagonia

\section{Introduction}

Leptospirosis is the most widespread zoonosis in the world. Usually, it is transmitted between wild domestic mammals and humans through contaminated water or direct exposure to urine of infected animals. Leptospires can persist in natural environments for long periods of time; while this largely depends on the ability of the bacteria to adapt to a wide range of animals, the pathogen can also survive in water as well (Smith and Zochowski 2011).

Studies on leptospirosis in Chile have reported a high prevalence of infection: $37 \%$ in dogs, $88.7 \%$ in cattle, $24.9 \%$ in sheep, $7.1 \%$ in horses, and $69.9 \%$ in swine; see review by (Zunino and Pizarro 2007). However, only a few studies have investigated the prevalence of Leptospira spp. in wild animals. For example, only the prevalence of Leptospira spp. in wild rodents is currently known (47.2\%); see reviews by (Zamora and Riedemann 1999; and Zunino and Pizarro 2007).

The North American mink (Neovison vison) is a semiaquatic mustelid that was introduced in Chile in the 1930s (Jaksic et al. 2002). Currently, the species has outgrowth considerably in number and distribution. The

\footnotetext{
* Correspondence: gmedina@unab.cl

${ }^{1}$ Facultad de Ecologia y Recursos Naturales, Universidad Andres Bello, República 252, Santiago, Chile

Full list of author information is available at the end of the article
}

mink is now widely distributed throughout the riverine and marine habitats of the Patagonian lacustrine in both Argentina and the south of Chile (from $38^{\circ} \mathrm{S}$ latitude to Tierra del Fuego Island and adjacent archipelagos $55^{\circ} \mathrm{S}$ ) (Medina 1997; Fasola et al. 2011). Mustelids are among the animals considered susceptible to infection with Leptospira; importantly, rodents are not only the primary reservoir of Leptospira, but also are an important part of the diet of minks. Additionally, the fact that minks often come into direct or indirect contact with different domestic animals suggests that inter-animal disease transmission events or potential human-transmission events are possible (Ullmann and Langoni 2011). While the role of minks as potential reservoir of Leptospira has not been determined yet, this role cannot been discarded as many emerging human, domestic animal, and wildlife diseases are usually maintained in specific reservoirs, many of which are rarely identified see reviews by (Adler and de la Peña. 2010; and by Smith and Zochowski 2011, Lau et al. 2012). Furthermore, Leptospira transmission is very complex, in fact, this is a pathogen of multiple hosts, which often resides in one or more epidemiologically connected populations (Haydon et al. 2012). The complexity of Leptospira transmission along with the abundance of mink populations indicates that minks may be an important link in the 
ecology of leptospires, especially due to their wide distributions, semiaquatic live, and diet (Medina 1997; Millán et al. 2009; Moinet et al. 2010; Sepúlveda et al. 2011). In this study, we determined and characterized the presence of pathogenic Leptospira species in North American minks in Southern Chile.

\section{Materials and methods}

\section{Sample collection}

During September 2011 to March 2012 we trapped 57 minks (39 males and 18 females) using leg hold soft catch traps and cage traps. The animals were captured in ten study areas within three Southern Chilean districts (Los Rios, Los Lagos, and Aysén), between $39^{\circ} \mathrm{S}$ to $45^{\circ} \mathrm{S}$ (Figure 1). These areas support a large diversity of habitats and species, including domestic and native animals, such as cows (Bos taurus), horses (Equus ferus caballus), sheep (Ovis aries), dogs (Canis lupus familiaris), cats (Felis silvestris catus), foxes (e.g. Lycalopex spp.), and otters (Lontra provocax). The coordinates of the traps were determined with a global positioning system (GPS). Once under anesthesia, with ketamine-dexmedetomidine in a dose of $10-0.025 \mathrm{mg} / \mathrm{kg}$ IM respectively, two blood samples (3-5 ml each) were collected by jugular venipuncture (one blood sample was collected using tubes with EDTA and the other sample was collected in tubes with cell buffer lysis). The minks were then euthanized with Tiopental $^{\ominus}$ (Biosano S.A., Santiago, Chile) doses for postmortem kidney tissue collection (collected in alcohol). All animal trapping and handling were performed according with ethical protocols of the Committee of Ethic of the Universidad Andrés Bello and the National Commission for Science and Technology. Samples of blood and kidney collected in the field were frozen and transported to the laboratory for further analysis.

\section{Laboratory analysis}

Total DNA from blood and kidney was extracted with the QIAamp DNA Mini Kit (Qiagen ${ }^{\bullet}$, Germany). On three samples per individual (two blood and one kidney), we used PCR to screen for Leptospira spp. as previously described by Lester and LeFebvre, 2003. To determine

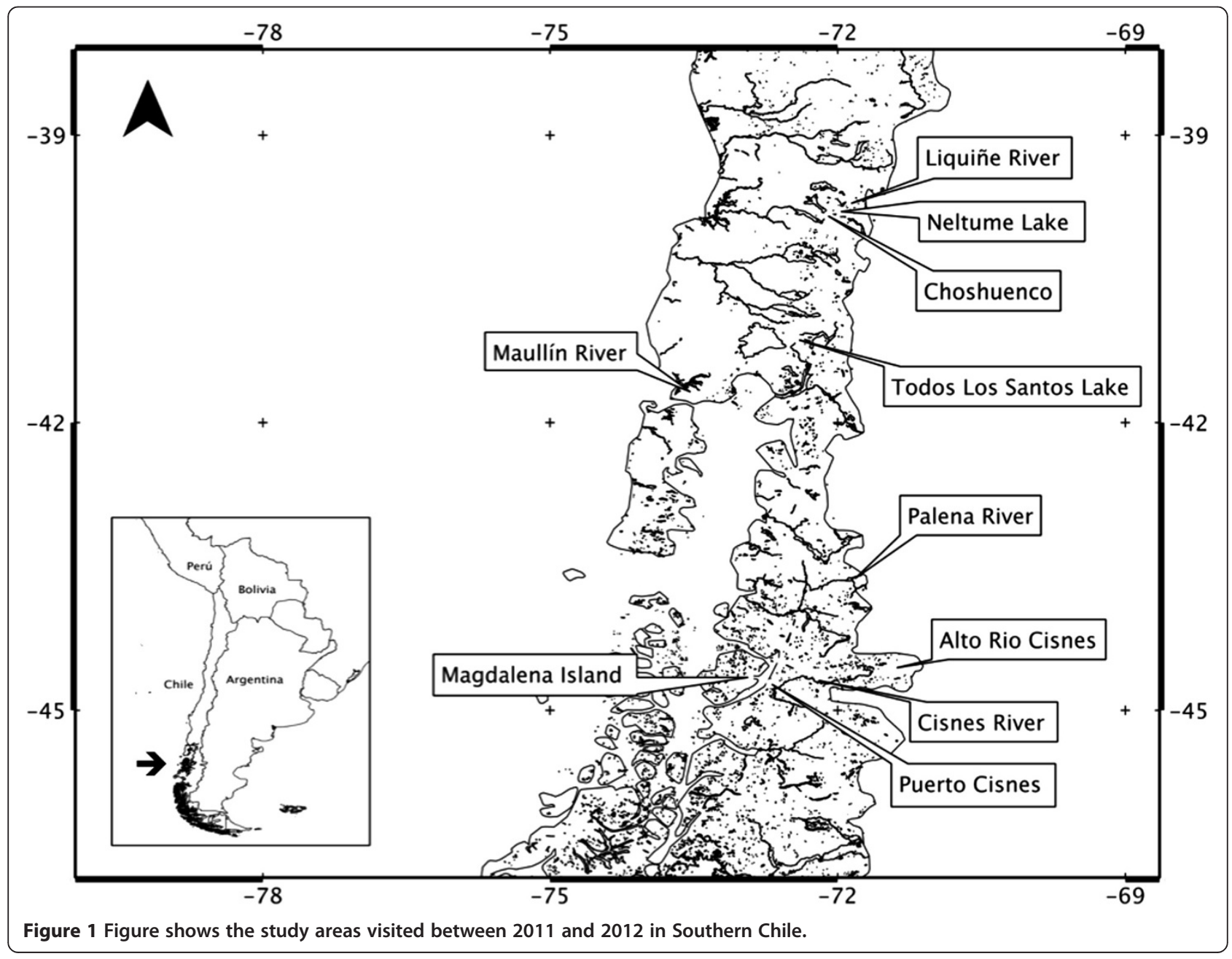


the species of Leptospira present in the positive samples, the amplified DNA (571 bp) of nine representative samples were sequenced at GenYtec (Santiago, Chile) using the ABI PRISM 310. To predict the species, sequences were compared with the GenBank database using the BLAST algorithm (http://www.ncbi.nlm.nih.gov/BLAST).

\section{Findings}

This study reports for the first time the prevalence of pathogenic Leptospira species in the American mink in the Chilean Patagonia. Among all the mink tested, 31 individuals corresponding to $55.6 \%$ (95\% confidence interval $=24,8-86,4)(21$ males and 10 females $)$ were positive for the PCR detection of pathogenic Leptospira spp. (Table 1). Seven animals tested positive for both, blood and kidney samples; eighteen of them tested positive for blood and only six for kidney samples. This suggests that more than one sample per individual facilitates the detection of Leptospira by PCR. In eight of the ten locations where samples were collected, we obtained positive results; specifically, only the location of Choscuenco and Rio Cisnes were negative (Table 1 and Figure 1). The location with the higher number of positive samples $(n=8)$ was Isla Magdalena; however, we collected samples from 15 individuals in this location.

Nine positive samples from different minks and from different locations were selected for sequencing of the $571 \mathrm{bp}$ amplicon of the 16S ribosomal RNA (rRNA) (Table 1). The BLAST algorithm was used to (i) validate that the amplified PCR products correspond with Leptospira species and to (ii) predict the putative pathogenic species. We identified sequences closely related to two of the Leptospira pathogenic species. Leptospira interrogans was putatively predicted in five samples from three locations (i.e., Palena, Alto Rio Cisnes, and Islas Magdalena) and samples closely related to Leptospira borgpetersenii in four samples from four locations (i.e., Liquiñe, Neltume, Todos los Santos, and Alto Rio Cisnes) (Table 1). Our matches showed approximately $97 \%$ of nucleotide identity with the Leptospira species mentioned above. However, these findings need to be validated though the analysis of the complete $16 \mathrm{~S}$ rRNA gene.

We report for the first time evidence of pathogenic Leptospira in alien North American mink in South America. In this study, we used PCR to detect the pathogen; previous studies have used traditional detection methods (e.g., microscopic agglutination test [MAT]); while these methods are not easily compared, here we discuss the prevalence previously identified by other authors in comparison with our findings, regarding of the method used. Importantly, we identified a higher prevalence $(55.6 \%$, with $95 \%$ confidence interval $=24,8-86$, 4) compared with previous reports of $23.5 \%$ of Leptospira in wild animals in Spain (Millán et al., 2009), which used the MAT to detect the presence of Leptospira. Another study reported by Moinet et al. (2010) identified a prevalence of $86 \%$ in wild American mink in France MAT detection. The same study detected by PCR a renal carriage of $26 \%$ on free-ranging American minks. The fact that we detected pathogenic species of Leptospira is relevant to both human and wild species health. Prevalence was high and transversal to almost all study sites, which are characterized by a mixture of natural forest and human activities. A previous study by Ghneim et al. (2007) showed that dogs in rural areas were more likely to have been in contact with contaminated water

Table 1 Number of positive samples and predicted Leptospira species in each study location

\begin{tabular}{|c|c|c|c|c|}
\hline Location & Environment & Sample size & $\begin{array}{l}\text { Number of positive minks }{ }^{a} \\
\text { (sequenced samples) }\end{array}$ & $\begin{array}{l}\text { Putative species of Leptospira } \\
\text { (number of samples) }\end{array}$ \\
\hline Liquiñe & Riverine & 3 & $2(1)$ & L. borgpetersenii (1) \\
\hline Neltume & Lacustrine & 5 & $3(1)$ & L. borgpetersenii (1) \\
\hline Choscuenco & Lacustrine & 3 & 0 & - \\
\hline Todos los Santos & Lacustrine & 8 & $5(1)$ & L. borgpetersenii (1) \\
\hline Maullín & Palustre & 6 & 5 & Not sequenced \\
\hline Palena & Riverine & 1 & $1(1)$ & L. interrogans (1) \\
\hline Alto Rio Cisnes & Riverine & 5 & $4(3)$ & L. interrogans (2), L. borgpetersenii (1) \\
\hline Isla Magdalena & Marine & 15 & $8(2)$ & L. interrogans (2) \\
\hline Puerto Cisnes & Marine & 6 & 3 & Not sequenced \\
\hline Rio Cisnes & Riverine & 5 & 0 & - \\
\hline Total & & 57 & 31 & \\
\hline
\end{tabular}

aPCR was conducted in three samples per individual (two blood and one kidney sample).

beptospira species were predicted according to the amplification of a 571 fragment of the 16S RNA gene. The best hit of BLAST was used to assign the putative species. A complete sequence of the $16 \mathrm{~S}$ rRNA gene would validate these findings. 
with leptospires, as compared with dogs in urban areas. This may indicate that the complexity of animal species, along with environmental factors (e.g., rainfall and standing water) in rural areas, could facilitate the contact with the pathogen. Minks likely become infected after preying on rodents. In fact, studies carried out in the same region as our study demonstrate that mink preys heavily on rodents (Medina-Vogel et al. 2013), and that rodents may become infected by contact with garbage and contaminated water (Smith and Rochowski 2011). In the south of Chile, rodents present high rates of Leptospira infection (Zunino and Pizarro 2007). In fact Muñoz-Zanzi et al. (2014) detected, by PCR, a 19.7\% Leptospira prevalence in rodents associated with agricultural fields, $25.9 \%$ associated with rural villages, $21.1 \%$ associated with wild rodents, and $12.3 \%$ associated with slums.

In this study, we found L. interrogans in Palena, Alto Rio Cisnes, and Isla Magdalena, which is a Leptospira species largely associated to rodents (Himsworth et al. 2013). In addition, we found L. borgpetersenii in Liquiñe, Neltume, Lake Todos los Santos, and Alto Rio Cisnes, which is a Leptospira species associated with cattle farming. Importantly, in locations where we found $L$. borgpetersenii, livestock production systems are common. Thus, it is tempting to speculate that minks could be infected by predating on wild native and alien rodents in locations where livestock is rare, as well by contact with garbage and contaminated water from horse, cattle, sheep, and pig urine in locations where livestock is common.

In 13 individuals, samples from kidneys were positive; this not only demonstrates the presence of chronic disease in minks, but also that they present renal carrier status, which is the central point of the epidemiology of leptospirosis. Consequently, minks in the south of Chile may excrete leptospires though the urine to the environment (Ullmann and Langoni 2011). These initial data indicates that American mink can serve as hosts for leptospirosis, thus serving as a tool for measuring environmental contamination with this pathogen. This study represents a first insight of the mink's role in the epidemiology of Leptospira in the south of Chile. This initial evidence suggests that mink abundance may pose a threat to human aquatic activities (e.g., canoeing, aquaculture, fisheries) and may as well affect the survival of aquatic species of conservation concern, such as the southern river otter (L. provocax) (Gaydos et al. 2007). Further investigation in order to identify source of infections, wild and domestic mammalian species involved, and the mechanism of transmission are necessary to provide evidence of the role of minks in the transmission of this important zoonotic pathogen.

\section{Competing interests}

The authors declare that they have no competing interests.

\section{Authors' contributions}

LS participated in the sequence alignment and have been involved in drafting the manuscript. LL participated in the sequence alignment and drafted the manuscript. CN carried out the molecular genetic studies and participated in the sequence alignment. MB carried out the acquisition of data and analyzed and wrote the manuscript. GM conceived of the study and participated in its design and coordination and have been involved in drafting the manuscript. All authors read and approved the final manuscript.

\section{Acknowledgements}

Funding was provided by the Chilean Fund for Science and Technology (Fondecyt) project 1100139: 'Presence of infectious diseases in wild species: the effect of alien invasive North American mink (Neovison vison) and the coexistence with stray dogs and cats.' We also want to thank René Monsalve, Rodolfo Tardone, and Sergio Navarrete for field assistance. And we thank Drs. Nelly Lakestani and Andrea Moreno for English editing and comments.

\section{Author details}

${ }^{1}$ Facultad de Ecologia y Recursos Naturales, Universidad Andres Bello, República 252, Santiago, Chile. ${ }^{2}$ Faculty of Veterinary Science, University of Chile, Santiago, Chile.

Received: 10 March 2014 Accepted: 22 September 2014

Published online: 14 October 2014

\section{References}

Adler B, De la Peña AM (2010) Leptospira and leptospirosis. Vet Microbiol 140:287-296

Fasola L, Muzio J, Chéhebar C, Cassini M, Macdonald D (2011) Range expansion and prey use of American mink in Argentinean Patagonia: dilemmas for conservation. Eur J Wildlife Res 57:283-294

Gaydos JK, Conrad PA, Gilardi KV, Blundell GM, Ben-david M (2007) Does human proximity affect antibody prevalence in marine-foraging river otters (Lontra canadensis)? H Wildl Dis 43:116-123

Ghneim GS, Viers JH, Chomel BB, Kass PH, Descollonges DA, Johnson ML (2007) Use of a case-control study and geographic information system to determine environmental and demographic risk factors for canine leptospirosis. Vet Res 38:37-50

Haydon DT, Cleaveland S, Taylor LH, Laurenson MK (2012) Identifying Reservoirs of Infection: A Conceptual and Practical Challenge. Emerg Infect Dis 8:1468-1473

Himsworth CG, Bidulka J, Parsons K, Feng AY, Tang P, Jardine CM, Patrick DM (2013) Ecology of Leptospira Interrogans in Norway rats (Rattus norvegicus) in an inner-city neighborhood of Vancuover, Canada. PLoS Negl Trop Dis 7:2270

Jaksic F, Iriarte A, Jiménez J, Martínez D (2002) Invaders without frontiers: cross-border invasions of exotic mammals. Biol Invasions 4:157-173

Lau CL, Skelly C, Smythe LD, Craig SB, Weinstein P (2012) Emergence of new leptospiral serovars in American Samoa-ascertainment or ecological change? BMC Infect Dis 12(1):19

Lester J, Lefebvre R (2003) Detection of Leptospira interrogans. Methods Mol Biol 216:193-200

Medina G (1997) A comparison of the diet and distribution of the southern river otter (Lutraprovocax) and mink (Mustela vison) in Southern Chile. J Zool 242:291-297

Medina-Vogel G, Barros M, Organ J, Bonesi L (2013) Evidence of competition between the Southern river otter and the alien invasive North American mink in marine habitats of southern Chile. J Zool 290:27-34

Millán J, Candela MG, López-Bao JV, Pereira M, Jiménez MA, León-Vizcañino L (2009) Leptospirosis in wild and domestic carnivores in natural areas in Andalusia, Spain. Vector Borne Zoonotic Dis 9:549-554

Moinet M, Fournier-Chambrillon C, Fontaine GA, Aulagnier S, Mesplède A, Blanchard B (2010) Leptospirosis in free-ranging endangered European mink (Mustela lutreola) and other small carnivores (Mustelidae, Viverridae) from southwestern France. J Wildl Dis 46:1141-1151

Muñoz-Zanzi C, Mason M, Encina C, Gonzalez M, Berg S (2014) Household characteristics associated with Rodent Presence and Leptospira infection in rural and urban communities from South Chile. Am J Trop Med Hyg http://ajtmh.org/cgi/doi/10.4269/ajtmh.13-0334

Sepúlveda MA, Munoz-Zanzi C, Rosenfeld C, Jara R, Pelican KM, Hill D (2011) Toxoplasma gondii in feral American minks at the Maullin river, Chile. Vet Parasitol 175:60-65 
Smith RM, Zochowski WJ (2011) Leptospirosis. In: Palmer SR, Soulsby L, Torgerson

PR, Brown David WG (eds) Zoonoses Biology, Clinical Practice, and Public Health Control, 2nd edn. Oxford university, New York

Ullmann LS, Langoni H (2011) Interactions between environment, wild animals and human leptospirosis. J Venom Anim Toxins 17:119-129

Zamora J, Riedemann S (1999) Wild animals as reservoirs of leptospirosis in Chile. Revision of studies in the country. Arch Med Vet 31:151-156

Zunino E, Pizarro R (2007) Leptospirosis. Puesta al día. Rev Chil Infectol 24:220-226

doi:10.1186/s40693-014-0019-x

Cite this article as: Barros et al:: High prevalence of pathogenic Leptospira

in alien American mink (Neovison vison) in Patagonia. Revista Chilena de

Historia Natural 2014 87:19.

Submit your manuscript to a SpringerOpen ${ }^{\circ}$ journal and benefit from:

- Convenient online submission

$\checkmark$ Rigorous peer review

- Immediate publication on acceptance

- Open access: articles freely available online

- High visibility within the field

- Retaining the copyright to your article

Submit your next manuscript at $\boldsymbol{\nabla}$ springeropen.com 